\title{
Monophyly, Taxon Sampling, and the Nature of Ranks in the Classification of Orb- weaving Spiders (Araneae: Araneoidea)
}

Robert J. Kallal ${ }^{1 *}$, Dimitar Dimitrov², Miquel Arnedo ${ }^{3,4}$, Gonzalo Giribet ${ }^{4}$, and Gustavo Hormiga ${ }^{1^{*}}$

${ }^{1}$ Department of Biological Sciences, The George Washington University, 2029 G St. NW, Washington, D.C. 20052, USA

${ }^{2}$ Department of Natural History, University Museum of Bergen, University of Bergen, P.O. Box 7800, 5020 Bergen, Norway

${ }^{3}$ Department of Evolutionary Biology, Ecology and Environmental Sciences, \& Biodiversity Research Institute (IRBio) Universitat de Barcelona, Avinguda Diagonal 643, Barcelona, Spain ${ }^{4}$ Museum of Comparative Zoology, Department of Organismic and Evolutionary Biology, Harvard University, 26 Oxford Street, Cambridge, MA 02138, USA

${ }^{*}$ Correspondence to be sent to: Department of Biological Sciences, The George Washington University, 2029 G St. NW, Washington, D.C. 20052, USA; E-mail: kallal@gwmail.gwu.edu, hormiga@gwu.edu

Abstract.- We address some of the taxonomic and classification changes proposed by Kuntner et al. (in press) in a comparative study on the evolution of sexual size dimorphism in nephiline spiders. Their proposal to re-circumscribe araneids and to rank the subfamily Nephilinae is fundamentally flawed as it renders the family Araneidae paraphyletic. We discuss the importance of monophyly, outgroup selection and taxon sampling, the subjectivity of ranks, and the implications of the age of origin criterion to assign categorical ranks in biological classifications. We explore the outcome of applying the approach of Kuntner et al. (in press) to 


\section{MONOPHYLY IN ORB-WEAVING SPIDERS}

the classification of spiders with emphasis on the ecribellate orb-weavers (Araneoidea) using a recently published dated phylogeny. We discuss the implications of including the putative sister group of Nephilinae (the sexually dimorphic genus Paraplectanoides) and the putative sister group of Araneidae (the miniature, monomorphic family Theridiosomatidae). We propose continuation of the phylogenetic classification put forth by Dimitrov et al. (2017) and we formally rank Nephilinae and Phonognathinae as subfamilies of Araneidae. Our classification better reflects the understanding of the phylogenetic placement and evolutionary history of nephilines and phonognathines while maintaining the diagnosability of Nephilinae. It also fulfills the fundamental requirement that taxa must be monophyletic, and thus avoids the paraphyly of Araneidae implied by Kuntner et al. (in press).

Keywords: Araneidae, Nephilinae, nomenclature, taxonomy, time banding

Specialists on particular groups almost always have a tendency to exaggerate ranks within their specialty, unless this is consciously perceived and corrected. They see differences more clearly, and their main occupation is likely to be analysis. Having special knowledge, the multiplicity of names is more helpful than difficult for them within a given field, and they do not always appreciate the great inconvenience experienced by the more general student to whom this field is only one of many. Treating one group as a special case they have no occasion to coordinate ranks with those in other groups and, often, little comprehension of the necessities of higher levels and the broader problems of classification.

G. G. Simpson (1945)

In a recent study on the evolution of sexual size dimorphism in nephiline spiders published in this journal, Kuntner et al. (in press) revised the classification of araneids. The nephiline clade includes several species that have been intensively studied (such as the golden orb weaver, 


\section{MONOPHYLY IN ORB-WEAVING SPIDERS}

Nephila clavipes), and thus a new system of scientific names can have a significant impact on the literature of the group well beyond systematic studies. As next generation sequencing costs decrease and the taxonomic sampling of genomic/phylogenomic studies becomes larger, it is crucial to reflect on how to use the resulting phylogenetic hypotheses for updating existing classifications. Sound taxonomic acts should be based on a thorough and unbiased treatment of previous works and should assess and take into consideration the taxon sampling context of all relevant studies, as the latter may require interpretation of monophyly in a context that may not necessarily be addressed in the study at hand.

The main goal of Kuntner et al.'s (in press) work is to study the evolution of sexual size dimorphism in nephiline spiders using a novel phylogeny based on anchored hybrid enrichment $(\mathrm{AHE})$ data. One outcome of their study is the proposal to formally resurrect the family rank of the araneid subfamily Nephilinae, which had been recently synonymized with Araneidae by Dimitrov et al. (2017). Kuntner et al.'s (in press) preferred topology does not require any changes in the current subfamilial classification of Araneidae, since all the groups as circumscribed by Dimitrov et al. (2017) remain monophyletic. Furthermore, Dimitrov et al.'s (2017) subfamilial relationships have been recently corroborated using both Sanger sequencing data (Kallal and Hormiga 2018) and transcriptomic data (Kallal et al. 2018). It is relevant to note that even the most complete araneid phylogeny to date (Scharff et al. in press) lacks subfamily ranks for all the taxa included in their analysis, as this speciose family remains largely undersampled and the addition of new taxa may substantially alter a number of relationships therein. While admitting that the assignment of Linnaean ranks in a classification is subjective (see a recent discussion in Giribet et al. 2016), Kuntner et al. (in press) attempt to provide objective grounds for their taxonomic acts. As we discuss here, we find their arguments unconvincing, but most importantly, we argue that because groups in a phylogenetic classification, regardless of the rank, should be monophyletic (Hennig 1966, Farris 1976), 


\section{MONOPHYLY IN ORB-WEAVING SPIDERS}

Kuntner et al.'s (in press) re-circumscription of Araneidae is fundamentally flawed as it renders the family paraphyletic.

Biological classifications aim to produce a natural and predictive conceptual framework for biology (e.g., Systematics Agenda 2000). There is an overwhelming consensus among systematists that phylogenetic relationships provide the logical basis for such a system. This paradigm, more than half a century after the English translation of Henning's (1950) Grundzüge einer Theorie der phylogenetischen Systematik, is far from novel, and it is reflected in most phylogenetically-informed revisions and current systematics textbooks. In one such text, Wheeler (2012:18) summarized this consensus by stating that systematists, regardless of their optimality criterion preferences, "all agree that groups must be monophyletic in the Hennigian sense, that classifications must match genealogy exactly" (see also a similar statement by Mishler 2009:63). The role of monophyly in such a classification system was succinctly articulated by Farris (1976), also long ago: “...the fundamental principle of phylogenetic classification can be correctly stated as the requirement that each monophyletic group must be a taxon, each taxon must be a monophyletic group, and the natural inclusion relationships of the monophyletic groups must be retained by the taxa."

\section{THE HIGHER LEVEL MOLECULAR SYSTEMATICS OF ARANEIDAE}

The orb-weaving spider family Araneidae is one of the most speciose groups in the order Araneae, with over 3,100 described species in 175 genera (World Spider Catalog 2019). Araneids also exhibit a wide diversity of morphologies, behaviors, and web architectures, making it difficult to diagnose both the family as a whole as well as some subfamily and suprageneric clades (but see 'Diagnosis' in Dimitrov et al. 2017). Araneids are members of the superfamily Araneoidea (the ecribellate orb-weavers), a large clade that includes 17 families 


\section{MONOPHYLY IN ORB-WEAVING SPIDERS}

and $26 \%$ of described spider diversity (Hormiga and Griswold 2014). Dimitrov et al. (2017) studied the phylogenetic relationships of Araneoidea based on a taxonomic sample of a total of 354 species, including representatives of all araneoid families. Sanger sequencing of six widelyutilized loci provided the data for their phylogenetic analysis. One of the goals of Dimitrov et al.'s (2017) study was to revise the family-level classification of araneoids. Their results required the removal of Arkys and close relatives from Araneidae and placed the clade of Nephila and close relatives as either sister-lineage of a clade with all other araneids (maximum likelihood and parsimony analyses) or sister-lineage to all araneids except phonognathines (also referred to as "zygiellines"), another araneid subfamily (Bayesian analysis). Kuntner et al.'s (in press) claim that Dimitrov et al. (2017) "treated Nephilinae as a subfamily of Araneidae with no explanation" is inaccurate (more than an entire printed page was devoted to Araneidae, which included sections on 'Diagnosis' and 'Putative synapomorphies'; Dimitrov et al. 2017: 244-245).

The genus Nephila was historically treated as an araneid (Simon, 1864, 1892; Roewer, 1942; Bonnet, 1955; Benoit, 1962; Brignoli, 1983; Heimer and Nentwig, 1983; Wunderlich, 1986, 2004) prior to the assignment of the family rank Nephilidae by Kuntner (2006). In the 1990s, based on cladistic analyses of morphological and behavioral data, the subfamily Nephilinae was inferred to be a lineage within Tetragnathidae (e.g., Coddington, 1990; Hormiga et al. 1995). The synonymy of Nephilidae under Araneidae by Dimitrov et al. (2017) was one of several classification changes implemented to fulfill the monophyly requirement for all family rank taxa and to limit the proliferation of araneoid spider families (Pararchaeidae, Holarchaeidae, Micropholcommatidae, and Sinopimoidae were similarly synonymized by Dimitrov et al. 2017). Dimitrov et al. (2017) found high bootstrap support and posterior probability for Araneidae (including nephilines), and for Nephilinae and Phonognathinae (which includes Zygiella, Phonognatha, and close relatives; the name Zygiellinae had been used for this lineage); nodal support for the monophyly of the remaining araneids (sometimes called "classic" araneids) was 


\section{MONOPHYLY IN ORB-WEAVING SPIDERS}

weaker. A similar pattern was found by Gregorič et al. (2015), Wheeler et al. (2017) - albeit with good support for "classic" araneids as well - and Kallal and Hormiga (2018), except with weak support for the placement of the genus Caerostris but good support for a clade including the remaining "classic" araneids. The systematics and phylogenetic relationships of Phonognathinae, another early diverging lineage of Araneidae, were also recently analyzed based on a broad taxon sample (80 araneid terminals in 48 genera plus 15 outgroup terminals) using a combination of molecular, morphological, and behavioral characters (Kallal and Hormiga 2018). This latter study also provided a taxonomic revision of three out of the five phonognathine genera. One of the more salient but perhaps overlooked results of the study of Kallal and Hormiga (2018) was the placement of the rare Australian araneid genus Paraplectanoides as sister group to the clade of Nephila and close relatives with high bootstrap support and posterior probability in all analyses in which it appeared. In a study with a significantly denser sample of Araneidae (92 araneid genera plus 22 outgroup terminals), Scharff et al. (in press) found an identical placement for Paraplectanoides (also with maximal nodal support) using the same markers and sequences from a different specimen. This robust araneid makes an unusual web under shrubs or dry fallen branches (Hickman 1976), and morphologically is quite different from nephilines (Davies 1988), much less other araneids. The resurrection of Nephilidae by Kuntner et al. (in press) and the proposed family rank for phonognathines (Phonognathidae) is based on results from an AHE analysis that includes six "classic" araneids, three phonognathines, and 23 nephilines. In addition, a rankless name was introduced for Araneidae sensu Dimitrov et al. (2017): "Orbipurae." While the work that hypothesizes a sister group relationship between Paraplectanoides and Nephilinae (Kallal and Hormiga 2018) was cited by Kuntner et al. (in press), and two of the authors are also co-authors of the study of Scharff et al. (in press) which finds an identical placement, this sister group relationship and its implications for the monophyly of Araneidae were not commented upon. Araneidae as circumscribed by Kuntner et al. (in press) is consequently a paraphyletic 


\section{MONOPHYLY IN ORB-WEAVING SPIDERS}

assemblage, and thus unacceptable in a cladistic classification (Fig. 1). The omission of Paraplectanoides is surprising, given that Kuntner et al. (in press) state that one of their "primary rationales for taxonomic decisions [is] monophyly."

Molecular phylogenetic studies of araneids vary both in the number of markers used and the taxon sample. Few studies include Paraplectanoides, as it is apparently rare and infrequently collected. Two such analyses use phylogenomic data, the rest Sanger sequences (in one case, combined with morphological characters). Kuntner et al. (in press) do not include Paraplectanoides, nor does Dimitrov et al. (2017) or Kallal et al. (2018). The latter study, and especially Kuntner et al. (in press), have small taxon samples, but the taxon samples of Dimitrov et al. (2017) and Kallal and Hormiga (2018) are extensive. Sanger loci have provided similar results to those of the AHE data analysis of Kuntner et al. (in press) for resolving araneid phylogeny, where the relationship between the putative subfamilies varied but with good support individually. As it is widely appreciated, one of the many strengths of next-generation sequencing lies in the orders of magnitude more loci that can be generated for phylogenetic inference relative to the handful of loci commonly used previously. While additional loci are often beneficial for resolving recalcitrant nodes, this should by no means imply a wholesale dismissal of phylogenetic hypotheses based on the commonly used mitochondrial and nuclear markers on the basis that these markers "typically [do] a poor job recovering older nodes" (Kuntner et al. in press). In fact, many deep nodes in Araneae, defined as being old or nested toward the root of the spider tree of life, have been hypothesized based on nucleotide sequence data from such markers and have been subsequently corroborated with phylogenomic datasets. For instance, the deepest node within Araneae, the split between Mesothelae and all other spiders (Opisthothelae), is supported in the unconstrained maximum likelihood tree based on six genes of Wheeler et al. (2017) with a bootstrap support of 100 and posterior probability of 1 . This node is approximately 366 (334-397) Ma on the calibrated analyses of Fernández et al. (2018). The 


\section{MONOPHYLY IN ORB-WEAVING SPIDERS}

clade Entelegynae diverged from Palpimanoidea 243 (214-274) Ma according to Fernández et al. (2018), and is well supported in the analyses of Dimitrov et al (2017). In the context of Kuntner et al. (in press), deep diverging instead refers to shallower, interfamilial divergences within Araneoidea. The araneoid clade is approximately 199 (175-230) Myr according to Fernández et al. (2018), which is congruent with the analyses of Dimitrov et al. (2017) using Sanger sequences in which araneoids were the focal taxon and thus much more densely sampled. The monophyly of Araneoidea is highly supported in analyses with both types of data. Similarly, a number of relatively deep nodes within Araneoidea are supported by limited loci, such as the tetragnathoid clade (Tetragnathidae + Mimetidae + Arkyidae), originally discovered with Sanger sequencing data (Blackledge et al. 2009) and subsequently corroborated by additional studies using the same markers and large taxon samples (Dimitrov et al. 2012, Gregorič et al. 2015, Benavides et al 2016, Dimitrov et al. 2017, Wheeler et al. 2017, Kallal and Hormiga 2018), as well as transcriptomic data (Fernández et al. 2018). Furthermore, Sanger sequencing data first suggested the diphyly of Nephila (Kuntner et al. 2013), a finding originally regarded as "ambiguous" (it was dated by Kuntner et al. (in press) at around 97-146 Ma) and has now been corroborated with the AHE dataset. These examples suggest that many of the nodes of the spider tree of life based on Sanger sequencing of standard markers are as likely to be supported by subsequent genomic-scale analyses as not, making a broad dismissal inadvisable.

What should be classified as a family (as opposed to a lower or higher Linnaean rank) is inherently subjective and Kuntner et al. (in press) rightly state "it is unlikely that taxonomic rank[s] will ever be free of subjective opinion." It is also important to note while the ICZN promotes stability of nomenclature, it should not be confused with stability of taxonomic hypotheses. The code is very explicit about this: "Nomenclature does not determine the inclusiveness or exclusiveness of any taxon, nor the rank to be accorded to any assemblage of 


\section{MONOPHYLY IN ORB-WEAVING SPIDERS}

animals" (ICZN 1999, 2012). The topological relationships within Araneidae are agnostic to nomenclatural changes, whether all lineages are included within a broad Araneidae (as formalized in the classification of Dimitrov et al. 2017) or each lineage is deemed its own family in a case of extreme splitting. However, the circumscription of a family in such a way that it explicitly violates the monophyly of another (as in Kuntner et al.'s (in press) classification) is not acceptable in a phylogenetic classification, even if the taxon that causes paraphyly of this latter group is not included in the analysis.

\section{TAXON SAMPLING AND OUTGROUPS}

The taxon sampling of a systematic study is a key issue to ensuing taxonomic actions, such as describing new higher taxa (i.e., genera and above) or re-circumscribing existing groups. In the case of Kuntner et al. (in press), there are 22 nephiline taxa with AHE data and some closely related outgroups, which is adequate to test its monophyly and to address taxonomic issues related to the phylogenetic structure within nephilines, such as erecting new genera. Indeed, Kuntner et al. (in press) partially do so, proposing the genus Trichonephila and elevating Indoetra from subgenus to genus to account for the diyphyly of Nephila in the former case and creating a monotypic genus sister group to a re-circumscribed Clitaetra for the latter. Although the AHE topology of Kuntner et al. (in press) renders Nephilinae sensu Kuntner 2006 (defined to include Herennia, Nephilengys, Nephilingis and Nephila) as paraphyletic with respect to the subfamily Clitaetrinae, this issue is not addressed in their classification (see also comments by Dimitrov et al. (2009) on the phylogenetic classification of Clitaetra and nephilines). However, for a study that aims to address the limits of the large and diverse family Araneidae, Kuntner et al.'s (in press) sampling is very limited, with only eight non-nephiline araneids and three taxa that are not araneids in any sense (two tetragnathids and one mimetid). It should be noted that neither of the two outgroups used in Kuntner et al.'s (in press) analysis are close relatives of 


\section{MONOPHYLY IN ORB-WEAVING SPIDERS}

Araneidae, whose sister group is the family Theridiosomatidae; araneids are part of a clade that includes another eight families, none of them represented in Kuntner et al.'s (in press) taxon sample (Fernández et al. 2018). Given that no recent phylogenetic analysis of araneoid relationships has suggested close propinquity between araneids and tetragnathids or mimetids, the selection of such distantly related outgroups, for which Kuntner et al. (in press) provide no rationale or justification, is perplexing. The presence of Paraplectanoides notwithstanding, a sampling of three phonognathines and six additional araneids hardly seems expansive enough for circumscribing new families or discussing the phylogenetic relationships of such a large and diverse family. This is in comparison to the sampling of Dimitrov et al. (2017), in which 32 araneids (23 "classic," five nephilines, and four phonognathines) were used for a denser sample of related lineages (including representatives all araneoid families), or Scharff et al. (in press) with a sample of 92 araneid genera and outgroups representing seven araneoid families. In any case, the monophyly of the groups including Phonognatha and close relatives, Nephila and close relatives, and the remaining araneids (sans Paraplectanoides) have not been called into question based on studies involving molecular data in the past several years, whether families, subfamilies, or otherwise unranked clades.

RANKS

Kuntner et al. (in press) make a number of specific arguments to support the family rank of Nephilidae on other grounds, including the age of origin of the lineage, morphology, phylogenetic distinctiveness and common use. Beyond ensuring that resulting named groups are monophyletic, the nature of such arguments is often specific to the taxon in question or the conventions of a research community, and reasoning for a given rank is idiosyncratic and as such subject to debate. Here, we address the arguments advocated by Kuntner et al. (in press) 


\section{MONOPHYLY IN ORB-WEAVING SPIDERS}

because they are presented as if those were objective grounds for what is ultimately a subjective decision.

Lineage age is not a standard metric for family rank in spider classification and is not a widely used criterion. The idea of using the age of origin of groups to assign classification ranks is often attributed to Hennig (e.g., Avise and Johns 1999, Holt and Jonsson 2004), although such a view goes further back. Simpson (1937), in discussing the lack of equivalency of the same taxonomic rank in different groups of organisms (such as families of insects and mammals), brings up the idea of establishing such groups (e.g., families) based on the time of origin. But Simpson quickly dismissed this time criterion as impractical, noting that it "quickly leads to confusion and to absurdity." Hennig (1966:182) lamented the fact that Simpson had not discussed in any detail why the time criterion would be impracticable ("It would take too long a digression to discuss this problem here..."), and went on to conjecture what Simpson's arguments might have been. Hennig's views are centered around the idea that what makes two groups comparable in a phylogenetic system is that such groups "stand in a sister-group relation to one another" and that as such they are of equal age and equivalent. Even modern advocates of the use of absolute dates of the nodes in phylogenetic trees as a "universal taxonomic yardstick" (Avise and Johns 1999) have eventually abandoned the temporal banding approach as not practical and counterproductive because it would necessitate "wholesale nomenclatural changes" which would "exacerbate the stability problem" of biological classification (Avise and Mitchell 2007, Avise and Liu 2011). Furthermore, as the proponents of temporal bands admit, "the exact temporal bands (windows of evolutionary time) to be associated with particular Linnean ranks are in principle arbitrary and, initially, would have to be ratified by the systematics community" (Avise and Liu 2011). Only after such community agreement has been established - which is not possible by the reason that a family can be sister group to two or more families, and therefore, by definition, they cannot all be of the same age - could the temporal banding be 


\section{MONOPHYLY IN ORB-WEAVING SPIDERS}

used as an objective criterion to standardize the assignment ranks in taxonomic classifications. We do not know of a single case in spider taxonomy in which the inferred age of a group has been used to assign a higher taxonomic rank. Kuntner et al. state that the ages of Tetragnathidae, Nephilidae, Araneidae, and Phonognathidae are comparable based on an ultrametricized tree constrained by the AHE topology and including the latter three lineages as Araneidae sensu Dimitrov et al. (2017) would result in an unduly large, old, and complex family. That is, however, a subjective argument and Kuntner et al. (in press) do not provide an explicit or quantitative rationale for their selection of time band other than it fits the family ranks of their choice. In addition, it is not clear how exactly the ultrametrization was carried and why relative branch lengths on Figures 2 and 3 seem to differ. Kuntner et al.'s (in press) AHE data analysis shows the common ancestor of Tetragnathidae (the only other family included with more than one species) to have a median age of approximately $285 \mathrm{Ma}$, whereas the common ancestors of Phonognathinae, Nephilinae, and Araneidae sensu Kuntner et al. (in press) are approximately half that age. To make their argument based on time, Kuntner et al.(in press) state that lumping anything with a median age of 200 myo or younger with its sister lineage would result in many families being synonymized. Similarly, the median of the age estimate for the split between Nephila and the remaining araneids in Garrison et al. (2016) is $94 \mathrm{Ma}$, so using a metric of 100 Ma to lump would result in lumping Nephilidae with Araneidae as well as 26 other families. This is a slippery slope of their own design, and the implication is that any age-based criterion that synonymizes Nephilidae would synonymize too many other spider families, that in their opinion, deserve to be ranked as families. Kuntner et al. (in press) highlight this time band using the blue vertical bar of their Figure 3, in which Nephilidae, Phonognathidae, Araneidae sensu Kuntner et al. (in press), and Tetragnathidae are present (but note that several families that are closer relatives to Araneidae and that would be nested in between are not represented). That is, the ages of the four putative families are comparable, and therefore their ranks are presented as objective. Although not explained in the text, it seems 


\section{MONOPHYLY IN ORB-WEAVING SPIDERS}

that the internodes subtending the most recent common ancestors of the putative families have been selected from a limited width of the possible temporal spectrum. Specifically, its oldest margin is just younger than the split between Nephilidae and Araneidae sensu Dimitrov et al. (2017), and its youngest margin is just older than the node indicating the common ancestor of Phonognathidae. This ultrametricized tree has no dating associated with it.

Kuntner et al.'s (in press) approach for assigning taxonomic ranks to spider families begs a logical question: What would be the implications of applying their ranking procedure to the remaining families of Araneae? We implemented a similar technique on the overall taxonomically denser and broader phylogenomic analysis of Fernández et al. (2018) (Fig. 2). We have added a colored "time band" to the internode zone apparently important to family rank in Kuntner et al. (in press) (their blue band). Note that phonognathine araneids are absent from this phylogeny, but such a date would be older than the age of Tetragnathidae and as such be irrelevant to this exercise. While there are 117 spider families recognized in the World Spider Catalog (2019), we center our discussion on the Superfamily Araneoidea because the taxon sampling of Fernández et al. (2018) emphasizes this latter clade. The resulting band covers an age of about 70-90 Ma. Nephila diverges from Araneidae sensu Kuntner et al. (in press) before this bar, as do Tetragnathidae and Mimetidae, thus satisfying Kuntner et al.'s (in press) comparable clade age criterion. However, application of this criterion objectively and beyond Araneidae, in which subfamilial splits prior to this bar deserve family status, would have an opposite effect than the one Kuntner et al.'s (in press) method endeavors to avoid: many new families would be required. Taken at its oldest ( 90 Ma), examples within Araneoidea in which an existing family would have to be split include Anelosimus and the rest of Theridiidae (119 Ma), Laminacauda and the rest of Linyphiidae (111 Ma), Spinanapis and Anapis in Anapidae (99 Ma), Ogulnius and the rest of Theridiosomatidae (94 Ma), and Pararchaea and the rest of Malkaridae (92 Ma). In an extreme example (outside of Araneoidea), the two members of 


\section{MONOPHYLY IN ORB-WEAVING SPIDERS}

Oecobius diverge at $112 \mathrm{Ma}$, implying that the two species in the same genus would require two families. While this latter age may be at least an effect in part of limited sampling of Oecobiidae, it points how inferred dates from a calibrated phylogeny can be affected by taxon sampling and phylogenetic methods, creating potential artifacts that obfuscate the alleged objectivity that time of origin is purported to provide. Naturally, more splits would be required if a younger point in the bar were selected. Furthermore, this exercise only takes the median of the $95 \%$ confidence interval into account; when the inherent uncertainty associated to time estimation is taken into account, a time banded definition of taxonomic ranks becomes even more challenging to implement (Avise and Mitchell 2007; Talavera et al. 2013). For example, Kuntner et al.'s (in press) own confidence intervals of the time estimate of key nodes spanned in some cases more than 200 Myr (Kuntner et al., Fig. 2).

In light of the importance of stability in biological nomenclature (e.g., Godfray and Knapp 2007), it seems necessary to consider how node age estimates may vary if such dates are to provide an objective criterion for establishing taxonomic ranks in classifications. Despite the increasing sophistication of methods to infer divergence times, the estimated age of many nodes across the tree of life contrast significantly and consistently with timeframes conveyed by the fossil record (Brown and Smith 2018). Known potential issues that can affect the inference of dates of origin include the fragmentary and incomplete nature of the fossil record and its dating and interpretation (Forey et al. 2004), data limitation and model inadequacy, biased sampling of major lineages representatives, and extreme state dependent molecular substitution rate heterogeneity (Beaulieu et al. 2015, Brown and Smith 2018). For example, Jin and Brown (2018) suggest that a substantial number of published BEAST divergence time estimates are likely to have been affected the choice of rates priors, which have a strong influence on divergence time estimation. Age inference is not trivial and requires the researcher to make long list of analytical choices, all of them potentially influencing the results of the analysis. These 


\section{MONOPHYLY IN ORB-WEAVING SPIDERS}

include among others the composition of the taxon sample, the type of data (DNA, amino acids, morphology, etc.), the use of fossil calibrations (where, when, priors; tip versus node dating), the type of dating analysis (BEAST, PhyloBayes, MrBayes), the use of concatenation versus multispecies coalescent, trimming/gap masking, model selection and partitioning, and the treatment of missing data. Tree inference, upon which hypotheses of monophyly and sister group relationships are based, is also the outcome of a long list of analytical choices. While this illustrates the conceptual richness and complexity of phylogenetic inference, it also points out to the naivete of implying that inferred age of origin can provide a solid, objective basis for biological classifications across the tree of life. Furthermore, classification systems and taxonomic practice should be consistent and applicable for both extant and extinct taxa and across taxonomic groups. The temporal banding approach advocated by Kuntner et al. (in press) cannot be applied consistently to extinct taxa. For example, how should we classify a hypothetical lineage that has originated $200 \mathrm{Ma}$ and went extinct $120 \mathrm{Ma}$ which shares synapomorphies with an extant family with crown group age of less than 100Ma? Such an approach, if applied beyond Araneidae would require substantial changes in the familial classification of spiders.

We need to address two additional criteria advanced by Kuntner et al. (in press) in support of their approach: the size (in terms of number of species) and the morphological complexity of the variously circumscribed groups they discuss. The difference in size between Araneidae sensu Dimitrov et al. (2017) and Araneidae sensu Kuntner et al. (in press) is minimal: a 1\% increase in the number of species if the former is preferred over the latter. We do not find that such difference in species composition provides a sound, objective argument to change the family ranks. Morphological complexity is briefly addressed (but not defined), although this ranking criterion also leaves much to be desired. Araneidae includes a vast number of morphological and behavioral traits, and none of these are treated as objective and essential for establishment 


\section{MONOPHYLY IN ORB-WEAVING SPIDERS}

of a family rank rather than a subfamily. The authors specifically note that the presence of a striated cheliceral boss is a synapomorphy of the nephiline clade, a character first proposed by Hormiga et al. (1995). Why this synapomorphy indicates family rank and others do not is also not explained. Notably, Paraplectanoides lacks cheliceral boss striae (Kallal and Hormiga, in prep.), so its potential inclusion in Nephilidae to support a reciprocal monophyly with Araneidae sensu Dimitrov et al. (2017) would not be a viable option if such clade (Nephilidae) needs to be defined by the surface structure of the cheliceral boss (or on their grounds of morphological complexity, for that matter, given the large number of autapomorphies of Paraplectanoides). An alternative would be to create a new family whose sole genus is Paraplectanoides and in doing so retaining the family rank of nephilines. We fail to see how such an action would improve the classification of araneids, other than providing a textbook example of Gregg's Paradox. Kuntner et al.'s (in press) argument based on phylogenetic distinctiveness is never explicitly defined in the paper, but as far as we understand, all clades are phylogenetically distinctive, by definition. "Prevailing community practice" is a social construct that would discourage certain taxonomic actions (e.g., the use of new nomenclature such as Trichonephila, Indoetra, Phonognathidae, and Orbipurae). Furthermore, while deferring to the World Spider Catalog (2019) as an invaluable resource for shared arachnological taxonomic knowledge is a generally wise idea, Kuntner et al. (in press) seem to acknowledge it subjectively. That is, 46 species of nephiline araneids are listed in the World Spider Catalog (2019), but only 37 of those are deemed as "currently valid" by Kuntner et al. (in press) (their Table 1). The remaining nine species have not been synonymized or otherwise treated taxonomically and thus remain valid names from a nomenclatural point in the sense of the ICZN, so it is unclear what the other merits of validity are according to Kuntner et al (in press). They conclude their taxonomic recommendations by arguing that their proposed rank-less name "Orbipurae" for the family Araneidae sensu Dimitrov et al. (2017) "begins to restore some measure of cladistic hierarchy within the vast and diverse superfamily Araneoidea, and should therefore stimulate comparative work." It is unclear what is 


\section{MONOPHYLY IN ORB-WEAVING SPIDERS}

actually being restored, given that the current classification that they aim to replace is fully hierarchical and explicitly phylogenetic. Their proposed rank changes do not alter the existing hierarchy of subfamilies and are not required by the new topological results based on AHE data. Finally, we are at loss about what stimulation may arise from adding a new rankless name for Araneidae sensu Dimitrov et al. (2017) and changing the ranks of the subfamilies.

\section{CONCLUSIONS}

Given the subjectivity of what should be assigned a family rank in a Linnaean classification, much of this discussion can be relegated to academic disagreement. Splitters will split and lumpers will lump. Simpson (1945:16) distilled in ironic terms the issue of the arbitrary nature of ranks: "The question, Precisely how large is the scope of a genus, a family, or an order? is not much more determinate than the question, Precisely how far is up?" Naturally, both Kuntner et al. (in press) and Dimitrov et al. (2017) have extensive discourses on the subjective merits of the family status of Nephilidae. More important, however, is overlooking previous results on the circumscription of the family Araneidae with regard to Paraplectanoides, as this relatively little known taxon directly impacts the monophyly of Araneidae. We believe that circumscribing Araneidae as in Dimitrov et al.'s (2017) classification better reflects our understanding of the phylogenetic placement and evolutionary history of nephilines while maintaining the diagnosability of Nephilinae, and thus avoiding the paraphyly of Araneidae implied by Kuntner et al. (in press). Phylogenetic inference of male and female size changes in nephilines and other araneids requires a sound taxonomic sample that should include not only Paraplectanoides, but also at least the putative sister group of Araneidae (the family Theridiosomatidae). Because Paraplectanoides exhibits extreme sexual size dimorphism and theridiosomatid adults are all small sized, their absence in a comparative study can potentially lead to error in the inference of ancestral states at deeper nodes of the nephiline phylogeny. Moving forward, we encourage 


\section{MONOPHYLY IN ORB-WEAVING SPIDERS}

following the basic principles of systematic research, including even-handed examination of prior relevant works before implementing taxonomic decisions and remembering that the taxon sampling and analyses of any given study should be considered in the larger research corpus.

\section{Taxonomy}

\section{Family Araneidae Clerck, 1757}

Type: Araneus Clerck, 1757

Type species: Araneus angulatus Clerck, 1757

Putative synapomorphies: The presence of modified setae (sustentaculum) on the tip of the fourth tarsi and the presence of a radix in the embolic division of the male palp are putative synapomorphies of Araneidae (Dimitrov et al. 2017); neither character is exempt of homoplasy.

Composition: The Araneidae lineage includes, among others, the subfamilies Nephilinae and Phonognathinae (see below), and currently groups 175 genera and 3,128 species (World Spider Catalog, ver. 20.0, 2019). Araneids are found worldwide; many additional species and genera remain to be described. No modern, suprageneric classification exists for the family, and many of the araneid genera have not been formally assigned to higher taxonomic groups (see Scharff et al. in press).

\section{Subfamily Nephilinae Simon, 1894 rank resurrected}

Type: Nephila Leach, 1815.

Type species: Aranea pilipes Fabricius, 1793.

Nephilinae Simon, 1894. Dimitrov et al. (2017), Scharff et al. (in press).

Nephilidae Simon, 1894. Kuntner (2006), Kuntner et al. (in press). 


\section{MONOPHYLY IN ORB-WEAVING SPIDERS}

Composition: The Nephilinae clade includes the genera Nephila Leach, 1815; Trichonephila Dahl, 1911; Clitaetra Simon, 1889; Indoetra Kuntner, 2006; Herennia Thorell, 1877;

Nephilengys L. Koch, 1872; and Nephilingis Kuntner, 2013.

\section{Subfamily Phonognathinae Simon, 1894 rank resurrected}

Type: Phonognatha Simon, 1894.

Type species: Epeira graeffei Keyserling, 1865.

Phonognatheae Simon, 1894.

Zygielleae Simon, 1929.

Zygiellidae Simon, 1929. Wunderlich (2004)

Zygiellinae Wunderlich, 2004. Gregorič et al. (2015), Kallal \& Hormiga (2018), Kallal et al. (2018).

Phonognathidae Simon, 1894. Kuntner et al. (in press).

Composition: The Phonognathinae clade includes the genera Artifex Kallal \& Hormiga, 2018;

Deliochus Simon, 1894; Leviellus Wunderlich, 2004; Phonognatha Simon, 1894; and Zygiella F. O. Pickard-Cambridge, 1902.

N.B. Several names, different spellings and circumscriptions have been used for the subfamily Phonognathinae. The systematic and comparative literature of these araneids is peppered with those names. In order to help understanding the meaning of such names we provide here a succinct account of these changes. Wunderlich (2004) raised Simon's (1929) Zygiellae (within his family Argiopidae in the Les Arachnides de France) to family rank (Zygiellidae) and circumscribed it to include the extant araneid genera Zygiella and Leviellus and the tetragnathid genus Chrysometa Simon, 1894. The monophyly of Zygiellidae sensu Wunderich (2004) has been consistently refuted by all phylogenetic analyses so far (as it contains both araneid and 


\section{MONOPHYLY IN ORB-WEAVING SPIDERS}

tetragnathid taxa). However, the name Zygiellidae was first used as a group that, in addition to Zygiella, also included the genera Phonognatha and Deliochus, by Kuntner et al. (2013) as "Zygiellidae", and was followed by Gregorič et al. (2015) as "Zygiellinae Wunderlich, 2004" and Kallal and Hormiga (2018) as Zygiellinae. This error was corrected by Kuntner et al. (in press).

FUNDING

This work was supported by US National Science Foundation (DEB 1457300 and 1457539 "Collaborative Proposal: Phylogeny and diversification of the orb weaving spiders (Orbiculariae, Araneae)" to G.H. and G.G.).

\section{ACKNOWLEDGMENTS}

Norman Platnick, Mark Harvey, Jimmy Cabra, and the Systematics Discussion Group of The George Washington University provided insightful comments of an earlier version of this paper. We are grateful to Thomas Pape for nomenclatural advice. We also thank Jonathan Coddington and two anonymous reviewers for their comments.

\section{REFERENCES}

Avise J.C., Johns G.C. 1999. Proposal for a standardized temporal scheme of biological classification for extant species. Proc. Natl. Acad. Sci. USA. 96:7358-7363.

Avise J.C., Liu J.-X. 2011. On the temporal inconsistencies of Linnean taxonomic ranks. Biol. J. Linn. Soc. 102:707-714. 
Avise J.C., Mitchell D. 2007. Time to standardize taxonomies. Syst. Biol. 56:130-133.

Beaulieu J.M., O'Meara B.C., Crane P., Donoghue M.J. 2015. Heterogeneous rates of molecular evolution and diversification could explain the Triassic age estimate for angiosperms. Syst. Biol. 64:869-878.

Benoit P.L.G. 1962. Les Araneidae-Nephilinae africains. Rev. Suisse Zool. 65:217-231.

Bonnet P. 1955. Bibliographia Araneorum. Toulouse: Douladoure.

Blackledge T.A., Scharff N., Coddington J.A., Szüts T., Wenzel J.W., Hayashi, C.Y., Agnarsson I. 2009. Reconstruction web evolution and spider diversification in the molecular era. Proc. Natl. Acad. Sci. USA. 106:5529-5234.

Benavides L.R., Giribet G. and Hormiga G., 2017. Molecular phylogenetic analysis of "pirate spiders"(Araneae, Mimetidae) with the description of a new African genus and the first report of maternal care in the family. Cladistics 33:375-405.

Brignoli P.M. 1970. Contribution a la connaissance des Symphytognathidae palearctiques (Arachnida, Araneae). Bull. Mus. Natn. His. Nat. 41:1403-1420.

Brown J.W., Smith, S.A. 2008. The past sure is tense: on interpreting phylogenetic divergence time estimates. Syst. Biol. 67:340-353. 


\section{MONOPHYLY IN ORB-WEAVING SPIDERS}

Coddington J.A. 1990. Ontogeny and homology in the male palpus of orb weaving spiders and their relatives, with comments on phylogeny (Araneoclada: Araneoidea, Deinopoidea). Smiths. Contr. Zool. 496:1-52.

Davies V. T. 1988. An illustrated guide to the genera of orb-weaving spiders in Australia. Mem. Queensland Mus. 25:273-332.

Dimitrov D., Lopardo L., Giribet G., Arnedo M.A., Álvarez-Padilla F., Hormiga G., 2011. Tangled in a sparse spider web: single origin of orb weavers and their spinning work unravelled by denser taxonomic sampling. P. Roy. Soc. Lond. B Bio. 279:1341-1350.

Dimitrov D., Benavides L.R., Arnedo M.A., Giribet G., Griswold C.E., Scharff N., Hormiga G. 2017. Rounding up the usual suspects: a standard target-gene approach for resolving the interfamilial phylogenetic relationships of ecribellate orb-weaving spiders with a new family-rank classification (Araneae, Araneoidea). Cladistics. 33:221-250. DOI: 10.1111/cla.12165

Dimitrov D., Benjamin S.P., Hormiga, G. 2009. A revised phylogenetic analysis for the spider genus Clitaetra Simon, 1889 (Araneae, Araneoidea, Nephilidae) with the first description of the male of the Sri Lankan species Clitaetra thisbe. Bull. Mus. Comp. Zool. 159:301-323.

Farris J.S. 1976. Phylogenetic classification of fossils with recent species. Syst. Zool. 25:271282.

Fernández R., Kallal R.J., Dimitrov D., Ballesteros J.A., Arnedo M.A., Giribet G., Hormiga, G. 2018. Phylogenomics, diversification dynamics, and comparative transcriptomics across the Spider Tree of Life. Curr. Biol. 28:1489-1497. 
Forey P.L., Fortey R.A., Kenrick P., Smith A.B. 2004. Taxonomy and fossils: a critical appraisal. Phil. Trans. R. Soc. Lond. B. 359:639-653.

Garrison N.L., Rodriguez J., Agnarsson I., Coddington J.A., Griswold, C.E., Hamilton C.A., Hedin M., Kocot K.M., Ledford J.M., Bond J.E. 2016. Spider phylogenomics: untangling the Spider Tree of Life. PeerJ. 4:e1719.

Giribet G., Hormiga G., Edgecombe G.D. 2016. The meaning of categorical ranks in evolutionary biology. Org. Divers. Evol. 16:427-430.

Godfray H.C.J., Knapp S. 2004. Taxonomy for the twenty-first century. Phil. Trans. R. Soc. Lond. B 359:559-739. doi:10.1098/rstb.2003.1457

Gregorič M., Agnarsson I., Blackledge T.A., Kuntner M. 2015. Phylogenetic position and composition of Zygiellinae and Caerostris, with new insight into orb-web evolution and gigantism. Zool. J. Linn. Soc. 175:225-243. doi:10.1111/zoj.12281

Heimer S., Nentwig W. 1983. Thoughts on the phylogeny of the Araneoidea Latreille, 1806 (Arachnida, Araneae). J. Zool. Syst. Evol. Res. 20:284-295.

Hennig W. 1966. Phylogenetic systematics. University of Illinois Press.

Hickman V. V. 1976. On Paraplectanoides crassipes Keyserling (Araneae: Araneidae). Bull. Br. Arachnol. Soc. 3:166-174. 


\section{MONOPHYLY IN ORB-WEAVING SPIDERS}

Holt B.G., Jonsson K.A. 2014. Reconciling hierarchical taxonomy with molecular phylogenies. Syst. Biol. 63:1010-1017.

Hormiga G., Eberhard W.G., Coddington, J.A. 1995. Web construction behavior in Australian Phonognatha and the phylogeny of nephiline and tetragnathid spiders (Araneae, Tetragnathidae). Austral. J. Zool. 43:313-364.

Hormiga G., Griswold, C.E. 2014. Systematics, phylogeny and evolution of orb-weaving spiders. Annu. Rev. Entomol. 59:487-512.

International Commission on Zoological Nomenclature. 1999. International Code of Zoological Nomenclature. 4th ed. International Trust for Zoological Nomenclature: London.

International Commission on Zoological Nomenclature. 2012. International Code of Zoological Nomenclature. 4th ed. [Incorporating Declaration 44, amendments of Article 74.7.3, with effect from 31 December 1999 and the Amendment on e-publication, amendments to Articles 8, 9, 10, 21 and 78, with effect from 1 January 2012]. Available from: http://www.nhm.ac.uk/hostedsites/iczn/code.

Jin Y., Brown R.P. 2018. Partition number, rate priors and unreliable divergence times in Bayesian phylogenetic dating. Cladistics 34:568-573. doi.org/10.1111/cla.12223.

Kallal R.J., Hormiga, G. 2018. Systematics, phylogeny, and biogeography of the Australasian leaf-curling orb-weaving spiders (Araneae: Araneidae: Zygiellinae), with a comparative analysis of retreat evolution. Zool. J. Linn. Soc. 184:1055-1141. DOI:10.1093/zoolinnean/zly014 


\section{MONOPHYLY IN ORB-WEAVING SPIDERS}

Kallal R.J., Fernández R., Giribet G., Hormiga G. 2018. A phylotranscriptomic backbone of the orb-weaving spider family Araneidae (Arachnida, Araneae) supported by multiple methodological approaches. Mol. Phylogenet. Evol. 126:129-140.

doi:10.1016/j.ympev.2018.04.007

Kuntner M. 2006. Phylogenetic systematics of the Gondwanan nephilid spider lineage Clitaetrinae (Araneae, Nephilidae). Zool. Scr. 35:19-62.

Kuntner M., Arnedo M. A., Trontelj P., Lokovsek T., Agnarsson I. 2013. A molecular phylogeny of nephilid spiders: evolutionary history of a model lineage. Mol. Phylogenet. Evol. 69:961-979. [+Appendix A] doi:10.1016/j.ympev.2013.06.008

Kuntner M., Hamilton C.A., Cheng R.-C., Gregorič M., Lupse N., Lokovsek T., Lemmon E.M., Lemmon A.R., Agnarsson I., Coddington J.A., Bond, J.E. 2019. Golden orbweavers ignore biological rules: phylogenomic and comparative analyses unravel a complex evolution of sexual size dimorphism. Syst. Biol.: early view. [will be included when the version with the final pagination is issued] doi:10.1093/sysbio/syy082

Mishler B.D. 2009. Three centuries of paradigm changes in biological classification: is the end in sight? Taxon 58:61-67.

Roewer C.F. 1942. Katalog der Araneae von 1758 bis 1940. Buchhandlung für Naturkunde und exakte Wissenschaften Paul Budy Bremen. 


\section{MONOPHYLY IN ORB-WEAVING SPIDERS}

Scharff N., Coddington J.A., Blackledge T.A., Agnarsson I., Framenau V., Szüts T., Hayashi

C.Y., Dimitrov D. (in press). Phylogeny of the orb-weaving spider family Araneidae (Araneae, Araneoidea). Cladistics (accepted pending minor revision).

Simon E. 1864. Histoire naturelle des araignees (Araneides). Librairie encyclopèdique de Roret: Paris.

Simon E. 1892. Histoire naturelle des araignees, 1st edn. Librairie encyclopèdique de Roret: Paris.

Simpson G.G. 1937. Supra-specific variation in nature and in classification from the view-point of paleontology. Am. Nat. 71:236-267.

Simpson G.G. 1945. The principles of classification and a classification of mammals. Bull. Amer. Museum Nat. Hist. 85:1-350.

Systematics Agenda 2000. Systematics Agenda 2000: charting the biosphere. Technical Report. New York: Systematics Agenda.

Talavera G., Lukhtanov V. A., Pierce N.E., Vila R. 2013. Establishing criteria for higher-level classification using molecular data: the systematics of Polyommatus blue butterflies (Lepidoptera, Lycaenidae). Cladistics 29:166-192. doi:10.1111/j.1096-0031.2012.00421.x

Wheeler W.C. 2012. Systematics: a course of lectures. Chichester: Wiley-Blackwell. 
Wheeler W.C., Coddington J.A., Crowley L.M., Dimitrov D., Goloboff P.A., Griswold C.E., Hormiga G., Prendini L., Ramírez M.J., Sierwald P., Almeida-Silva L., Álvarez-Padilla F., Arnedo M.A., Benavides Silva L.R., Benjamin S.P., Bond J.E., Grismado C.J., Hasan E., Hedin M., Izquierdo M.A., Labarque F.M., Ledford J., Lopardo L., Maddison W.P., Miller J.A., Piacentini L.N., Platnick N.I., Polotow D., Silva-Dávila D., Scharff N., Szüts T., Ubick D., Vink C.J., Wood H.M., Zhang J.X. 2017. The spider tree of life: phylogeny of Araneae based on target-gene analyses from an extensive taxon sampling. Cladistics 33:574-616. doi:0.1111/cla.12182

World Spider Catalog. 2019. World Spider Catalog. Version 19.5. Natural History Museum Bern, online at http://wsc.nmbe.ch, accessed on 7 January 2019. doi: 10.24436/2

Wunderlich J. 1986. Fossile Spinnen in Bernstein und ihre heute lebenden Verwandten. Erich Bauer bei Quelle and Meyer, Wiesbaden.

Wunderlich J. 2004. Fossil spiders (Araneae) of the superfamily Dysderoidea in Baltic and Dominican amber, with revised family diagnoses. Beitr. Araneol. 3:633-746. 
Wheeler W.C., Coddington J.A., Crowley L.M., Dimitrov D., Goloboff P.A., Griswold C.E., Hormiga G., Prendini L., Ramírez M.J., Sierwald P., Almeida-Silva L., Álvarez-Padilla F., Arnedo M.A., Benavides Silva L.R., Benjamin S.P., Bond J.E., Grismado C.J., Hasan E., Hedin M., Izquierdo M.A., Labarque F.M., Ledford J., Lopardo L., Maddison W.P., Miller J.A., Piacentini L.N., Platnick N.I., Polotow D., Silva-Dávila D., Scharff N., Szüts T., Ubick D., Vink C.J., Wood H.M., Zhang J.X. 2017. The spider tree of life: phylogeny of Araneae based on target-gene analyses from an extensive taxon sampling. Cladistics 33:574-616. doi:0.1111/cla.12182

World Spider Catalog. 2019. World Spider Catalog. Version 19.5. Natural History Museum Bern, online at http://wsc.nmbe.ch, accessed on 7 January 2019. doi: 10.24436/2

Wunderlich J. 1986. Fossile Spinnen in Bernstein und ihre heute lebenden Verwandten. Erich Bauer bei Quelle and Meyer, Wiesbaden.

Wunderlich J. 2004. Fossil spiders (Araneae) of the superfamily Dysderoidea in Baltic and Dominican amber, with revised family diagnoses. Beitr. Araneol. 3:633-746. 


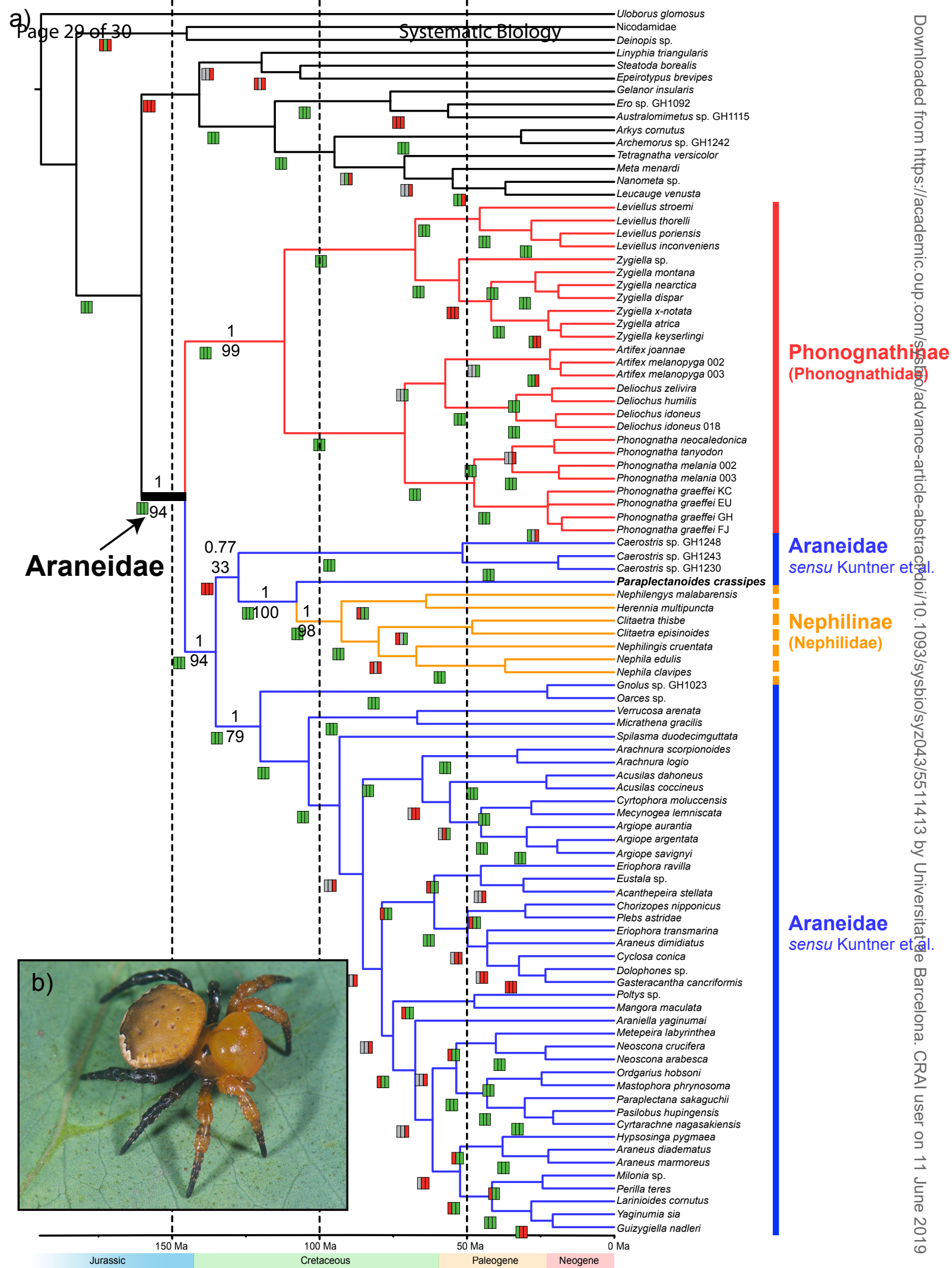


a) $) \sqrt{\text { systematic Biology }}$

b)
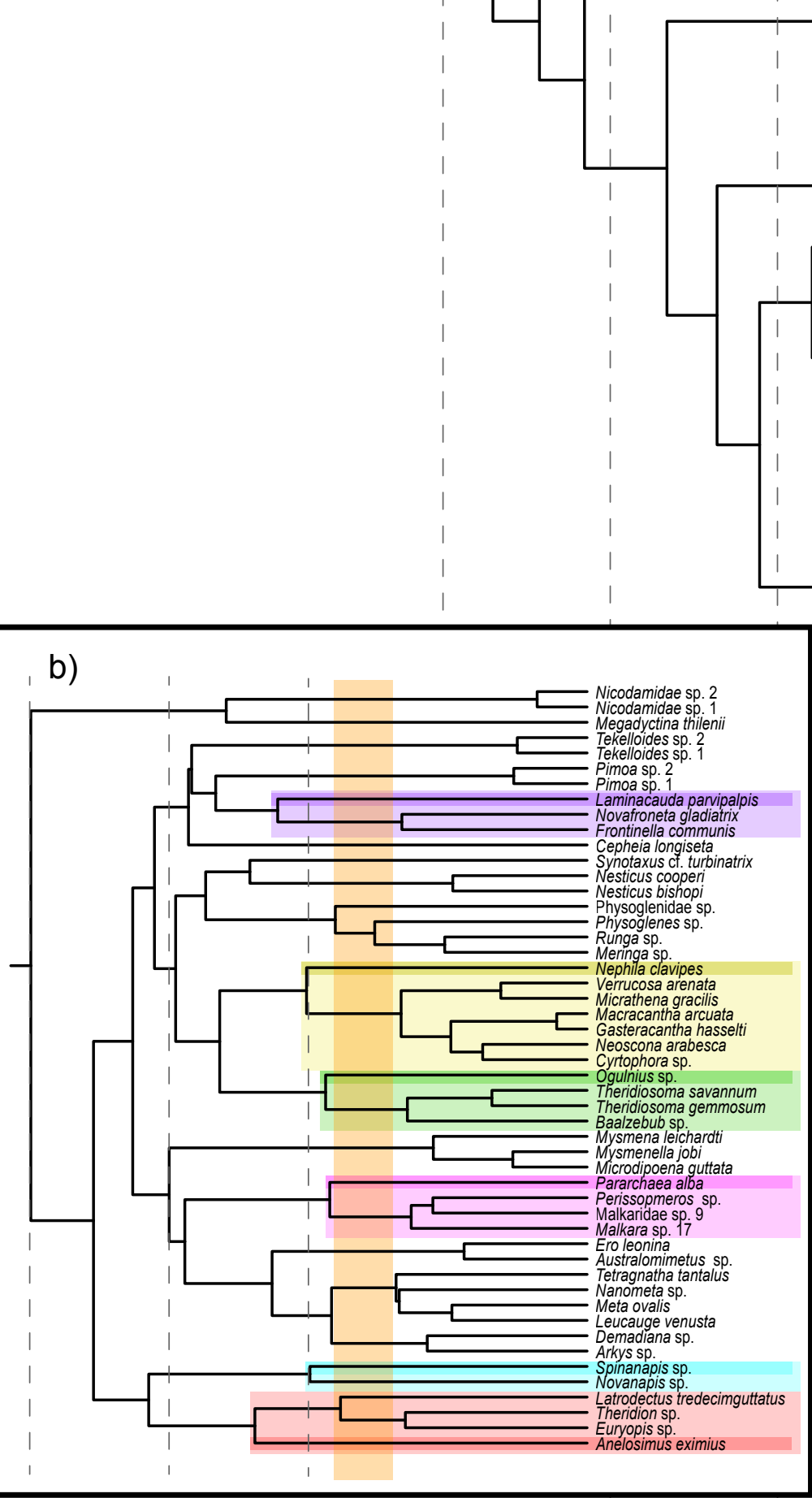